Original article

\title{
Complete sequence of the ANKK1 gene in Mexican-Mestizo individuals with obesity, with or without binge eating disorder
}

\author{
Adriana Palacios ${ }^{\mathrm{a}}$, Patricia Canto ${ }^{\mathrm{a}, \mathrm{b}}$, María Elena Tejeda ${ }^{\mathrm{a}}$, Sylvana Stephano ${ }^{\mathrm{b}}$, \\ Hassell Luján ${ }^{a}$, Eduardo García-Garcíab ${ }^{\mathrm{b}}$, David Rojano-Mejía ${ }^{c}$, Juan Pablo Méndez ${ }^{\mathrm{a}, \mathrm{b}, *}$ \\ a Unidad de Investigación en Obesidad, Facultad de Medicina, Universidad Nacional Autónoma de México, Ciudad de México, Mexico \\ b Clínica de Obesidad, Instituto Nacional de Ciencias Médicas y Nutrición "Salvador Zubirán”, Ciudad de México, Mexico \\ “Unidad de Medicina Física y Rehabilitación Centro, UMAE, Hospital de Traumatología y Ortopedia “Lomas Verdes”, Instituto Mexicano del Seguro Social, \\ México, D.F., Mexico
}

\section{A R T I C L E I N F O}

\section{Article history:}

Received 14 May 2018

Received in revised form 26 July 2018

Accepted 27 July 2018

Available online 16 August 2018

\section{Keywords:}

ANKK1

Genetic variants

Obesity

Binge eating disorder

\begin{abstract}
A B S T R A C T
Background: The aim of this study was to investigate if Mexican-Mestizo individuals with obesity, with or without binge eating disorder (BED), exhibited mutations or other type of genetic variants in the sequence of ANKK1.

Subjects and methods: Fifty unrelated individuals (21-53 years of age) with obesity, of Mexican-Mestizo ethnic origin were included; 25 of them had BED and 25 presented obesity without BED. The diagnosis of BED was based on criteria proposed in the Diagnostic and Statistical Manual of Mental Disorders (DSM5). Besides, we also analyzed 100 individuals with normal body mass index. DNA from blood leukocytes was amplified by the polymerase chain reaction and all exons of ANKK1 were sequenced.

Results: After ANKK1 sequencing we did not find any mutations; however, we observed various polymorphisms. One polymorphism, rs4938013 in exon 2 showed an association with obesity, whilst rs1800497 (also known as Taq1A) in exon 8, showed an association with BED $(P=0.020)$. Remarkable, for this study, the number of individuals for both polymorphisms for and additive model was sufficient to derive strong statistical power $(80 \%$, with a $\mathrm{P}<0.05)$.

Conclusions: To our knowledge, this constitutes the first report where the complete sequences of ANKK1 has been analyzed in individuals with obesity, with or without BED. No mutations were found; however, one polymorphism was associated with obesity, with or without BED, and another one was associated with BED.
\end{abstract}

() 2018 Elsevier Masson SAS. All rights reserved.

\section{Introduction}

Obesity is a multifactorial disease that has reached epidemic proportions worldwide. In Mexico, the last National Survey demonstrated that the prevalence of obesity has augmented from $21.5 \%$ in 1993 , to $33.3 \%$ in 2016 [1]. It has been established that obesity is associated with several psychiatric disorders [2,3], being binge eating disorder (BED) one of them [4]. One of these entities is BED which is characterized by recurrent-persistent episodes of uncontrolled binge eating with distress, in the absence of regular compensatory behaviors [5]. According to the WHO World Mental Health (WMH) Survey Initiative [6] performed in several countries, including Mexico, lifetime prevalence has been estimated at an

\footnotetext{
* Corresponding author at: Unidad de Investigación en Obesidad, Facultad de Medicina, Universidad Nacional Autónoma de México, Ciudad de México, Mexico. E-mail address: jpmb@unam.mx (J.P. Méndez).
}

average of $1.9 \%$, across surveys. Individuals presenting BED, have a significantly higher BMI than those without a history of this eating disorder. Furthermore, individuals with BED are more susceptible to have other concomitant psychiatric disorders, like depression or anxiety [7].

At present, the precise etiology of BED has not been determined. This pathological entity has been considered a multifactorial disease where diverse risk factors, including genetics, play a role on its onset. It has been estimated that BED presents a heritability between $41 \%$ and $57 \%$ [8,9], which suggests that genetic variations could play an important role in its pathogenesis. Several candidate genes have been analyzed; however, the results of these studies have not been conclusive [10].

Dopamine receptor type 2 (DRD2), a G-protein coupled receptor, located on the postsynaptic dopaminergic neurons, is centrally involved in the reward-mediating mesocorticolimbic pathways. This receptor has been the focus of many studies investigating genetic variations that could be associated with 
addictive behavior and with reward mechanisms [11,12]. One of the most frequently studied functional polymorphisms of the D2 receptor was Taq1A (dbSNP_rs1800497: c.2137 G > A, p.Glu713Lys). For many years, Taq1A was thought to be located on the $3^{\prime}$ untranslated region of DRD2; however, subsequent studies demonstrated that this single-nucleotide polymorphism (SNP) was not a part of $D R D 2$, but of an adjacent gene named as ankyrin repeat and kinase domain containing 1 (ANKK1) [13].

It has been demonstrated that ANKK1 is activated by apomorphine, a dopaminergic agonist, indicating a potential connection between ANKK1 and the dopaminergic system. Besides, due to its proximity with $D R D 2$, it has been suggested that ANKK1 may play an important role in modifying dopaminergic signaling, following drug exposure [14].

Although obesity has been associated with BED, there are obese individuals that never present BED. Since previous studies have only analyzed polymorphisms in ANKK1 [11,15-18] and have not searched for the presence of mutations in the open reading-frame of this gene, as a possible cause of obesity with or without BED, the aim of this study was to investigate if individuals with obesity with or without BED, presented mutations in the sequence of ANKK1.

\section{Subjects and methods}

\subsection{Subjects}

The Human Research Committees of the participating institutions approved the study. Informed consent was obtained from all individuals before been included. All procedures performed were in accordance with the ethical standards of the institutional and/or national research committees and with the 1964 Helsinki declaration and its later amendments or comparable ethical standards.

Twenty-five unrelated individuals presenting obesity with BED (9 males and 16 females) and twenty-five unrelated individuals presenting obesity without BED (12 males and 13 females) were recruited from the Clinic of Obesity and Eating Disorders of the Instituto Nacional de Ciencias Médicas y Nutrición Salvador Zubirán. All patients were of Mexican-Mestizo ethnic origin. According to the National Institute of Anthropology, a MexicanMestizo is defined as a person who was born in Mexico, has a Spanish-derived last name, and has a family of Mexican ancestors back to the third generation [19]. The diagnosis of BED was determined by a psychiatrist of the clinic, who administered a semi-structured questionnaire to all individuals on a face-to-face mode. The diagnosis of this entity was based on those criteria proposed in the Diagnostic and Statistical Manual of Mental Disorders, Fifth Edition (DSM-5) [5].

Body height and weight were measured at baseline examination, with the subject in a standing position, wearing a hospital gown and without shoes. Height and weight were used to calculate body mass index (BMI) $\left(\mathrm{kg} / \mathrm{m}^{2}\right)$. Individuals were categorized as having a BMI of obesity if it was $\geq 30.0 \mathrm{~kg} / \mathrm{m}^{2}$. Besides, we measured body fat percentage by bio impedance using a Tanita scale (TBF 300a; Tanita Corporation, Itabashi-Ku, Tokyo, Japan).

Individuals with a previous diagnosis of bulimia nervosa, any psychotic disorder, substance abuse, alcoholism, or a serious medical/physical illness such as cancer, or heart disease, were excluded from the study.

In addition, 100 individuals were recruited as controls (38 males and 62 females). All of them were of Mexican-Mestizo ethnic origin and were donors at the Blood Bank of the Instituto Nacional de Ciencias Médicas y Nutrición Salvador Zubirán. All of them presented a normal BMI (BMI $=22.0 \pm 1.6 \mathrm{~kg} / \mathrm{m}^{2}$ for females, $\mathrm{BMI}=23.3 \pm 1.3 \mathrm{~kg} / \mathrm{m}^{2}$ for males), with ages ranging between 21-38 years and without any history of eating disorders; besides, these individuals did not present any history of major physical disorders, bulimia nervosa or a history of obesity, substance abuse, or alcoholism.

\subsection{Methods}

Genomic DNA was isolated from blood leukocytes using the salting out procedure described by Miller et al. [20]. DNA was amplified by PCR in $25 \mu \mathrm{l}$ of mixture reaction, containing $100 \mathrm{ng}$ of genomic DNA, $0.1 \mathrm{mM}$ dNTPs, $2.0 \mathrm{U}$ of KAPA Taq PCR Kit (KapaBiosystems, Massachusetts, USA), and $250 \mathrm{nM}$ of each specific set of ANKK1 primers. Primers were designed by us using Primer3web version 4.0.0 (http://primer3.ut.ee/). Due to its size, exon 8 of ANKK1 (1306 base pairs), was divided into five fragments. The sequences of the oligonucleotides, the size of the amplified products and the annealing temperatures are under request.

After amplification, PCR products were subjected to electrophoresis on $1.2 \%$ agarose gels and stained with Midori Green DNA Stain (Nippon Genetics Europe GmbH, Düren, Germany) to verify the correct size of the expected fragments. PCR products were purified by QIAEX II (QIAGEN GmbH, Hilden, Germany). DNA sequences (100 ng DNA template/reaction) were determined by cycle sequencing on an automated DNA sequencer 3500XL (Applied Biosystems Division, Foster City, CA, USA) using the DNA Sequencing Kit BigDye ${ }^{\mathrm{TM}}$ Terminator Cycle Sequencing Ready Reaction (PE Biosystems, Foster City, CA, USA). Sequencing was performed following the protocol supplied by the manufacturer.

\subsubsection{Statistical analysis}

We performed a cross-sectional study. Data from the overall patient population were summarized as mean and standard deviation. To evaluate differences between groups (control and case), an unpaired Student $t$-test was used.

Deviations from Hardy-Weinberg equilibrium and the differences of the alleles and genotypes frequencies between groups were assessed by $X^{2}$ tests. Multinomial logistic regression analysis was used to determine if a specific genotype is associated with obesity, with and without BED. Odds ratio (OR) with a 95\% confidence interval $(\mathrm{CI})$ and an associated p-value, was calculated as a measure of association. For multiple comparisons of the

Table 1

Clinical characteristics of individuals with obesity, with or without BED.

\begin{tabular}{|c|c|c|}
\hline Variables & $\begin{array}{l}\text { Individuals with obesity without BED } \\
\mathrm{N}=25\end{array}$ & $\begin{array}{l}\text { Individuals with obesity and BED } \\
\mathrm{N}=25\end{array}$ \\
\hline Sex, m/f (N) & $12 / 13$ & $9 / 16$ \\
\hline Age (years) & $30-52$ & $27-53$ \\
\hline BMI $\left(\mathrm{kg} / \mathrm{m}^{2}\right)$ & $38.6 \pm 5^{*}$ & $42.3 \pm 6.6^{*}$ \\
\hline Fat $(\%)$ & $39.2 \pm 2.6^{* *}$ & $42.2 \pm 3.7^{* *}$ \\
\hline
\end{tabular}

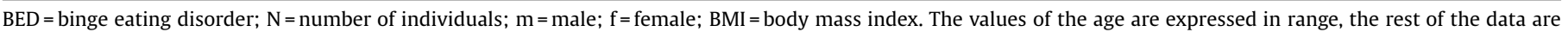

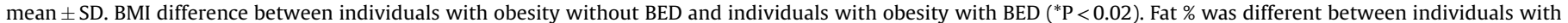
obesity without BED and individuals with obesity with BED $\left({ }^{* *} \mathrm{P}<0.0001\right)$. 
genetic models a post hoc false discovery rate (FDR) test was used. Statistical analyses were carried out using SPSS v.20.0 (SPSS Inc., Chicago, IL, USA), $P$ value $<0.05$ was accepted as statistically significant. Besides, the analyses of the ANKK1 sequences were performed using the Chromas 2.4.4 software.

\section{Results}

All individuals included $(n=50)$ presented obesity $(B M I>30.0$ $\mathrm{kg} / \mathrm{m} 2$ ), twenty-five of them also had BED. We observed that individuals with BED had the highest BMI and percentage of fat, when compared with individuals that only presented obesity; these differences were statistically significant $(P=0.029$ and $\mathrm{P}=0.0001$, respectively). Clinical characteristics of all individuals participating in the study are shown in Table 1.

After sequencing the coding region of the ANKK1 gene, we did not find any mutations. All changes found were polymorphisms, according to the NCBI Reference Sequence dbSNP (https://www. ncbi.nlm.nih.gov/snp/). We observed two polymorphisms in exon 2 (rs17115439 and rs4938013), one in exon 5 (rs7118900), one in exon 6 (rs11604671), and four in exon 8 (rs4938016, rs2734849, rs2734848 and rs1800497). All polymorphisms were in HardyWeinberg equilibrium $(P>0.05)$. Genotype and allele frequencies of all polymorphisms are presented in Table 2.

The rs1800497 polymorphism (also known as Taq1A polymorphism) located in exon 8 , showed an association with BED. Under an additive model the 713Lys genotype conferred a significant risk of $\mathrm{BED}$, with an odds ratio $(\mathrm{OR})=4.030$ and a $95 \%$ confidence interval $(\mathrm{CI})=1.201-13.526 ; P=0.020$; (Graphic 1 ) however, when we corrected with the FDR test, this difference was not significant $(P=0.16)$. Also, the $G$ allele was associated with a significant risk of BED (OR=3.431, 95\% CI: 1.461-8.057; $P=0.003$ ) and this association remained even after the FDR correction $(P=0.031)$. All other seven polymorphisms showed no significant differences, regarding individuals with obesity and BED compared with individuals with obesity without BED, under any genetic models analyzed (data not shown).

Taking into consideration that all individuals included in this study had obesity and to prove if the rs 1800497 polymorphism was associated only with BED or with obesity, besides the possibility that any of the other seven polymorphisms could be associated with obesity, we compared the genotype and allele frequencies of these 50 individuals (100 alleles) with 100 subjects (200 alleles) with a normal BMI (20-24.9 kg/m2), with ages between $21-38$ and without any history of eating disorders. All polymorphisms were in Hardy-Weinberg equilibrium $(P>0.05)$. Genotype and allele frequencies of rs4938013 and rs1800497polymorphisms are presented in Table 3.

Regarding the rs1800497 polymorphism, we observed that this SNP was not associated with obesity (data not shown). Interestingly, the rs 4938013 polymorphism located in exon 2 showed an association with obesity and this association was present under all

Table 2

Genotype and allele frequencies of ANKK1 polymorphisms in obese patients (with or without BED).

\begin{tabular}{|c|c|c|c|}
\hline dbSNP & Genotype frequencies & Individuals with obesity without BED $(\mathrm{N}=25)$ & Individuals with obesity and BED $(\mathrm{N}=25)$ \\
\hline rs17115439 in exón 2 & $\mathrm{C} / \mathrm{C}$ & $3(12.0 \%)$ & $3(12.0 \%)$ \\
\hline \multirow[t]{2}{*}{ (p.S85S) } & $\mathrm{C} / \mathrm{T}$ & $15(60.0 \%)$ & $12(48.0 \%)$ \\
\hline & $\mathrm{T} / \mathrm{T}$ & $7(28.0 \%)$ & $10(40.0 \%)$ \\
\hline \multirow[t]{2}{*}{ Allelle frequency } & $\mathrm{C}$ & $42.0 \%$ & $36.0 \%$ \\
\hline & $\mathrm{T}$ & $58.0 \%$ & $64.0 \%$ \\
\hline rs4938013 in exon 2 & $\mathrm{C} / \mathrm{C}$ & $2(8.0 \%)$ & $1(4.0 \%)$ \\
\hline \multirow[t]{2}{*}{ (p.I151I) } & $\mathrm{C} / \mathrm{A}$ & $7(28.0 \%)$ & $6(24.0 \%)$ \\
\hline & $\mathrm{A} / \mathrm{A}$ & $16(64.0 \%)$ & $18(72.0 \%)$ \\
\hline \multirow[t]{2}{*}{ Allelle frequency } & $\mathrm{C}$ & $22.0 \%$ & $16.0 \%$ \\
\hline & A & $78.0 \%$ & $84.0 \%$ \\
\hline rs7118900 in exon 5 & $\mathrm{G} / \mathrm{G}$ & $10(40.0 \%)$ & $9(36.0 \%)$ \\
\hline \multirow[t]{2}{*}{ (p.A239T) } & $\mathrm{G} / \mathrm{A}$ & $8(32.0 \%)$ & $8(32.0 \%)$ \\
\hline & $\mathrm{A} / \mathrm{A}$ & $7(28.0 \%)$ & $8(32.0 \%)$ \\
\hline \multirow[t]{2}{*}{ Allelle frequency } & $\mathrm{G}$ & $56.0 \%$ & $52.0 \%$ \\
\hline & A & $44.0 \%$ & $48.0 \%$ \\
\hline rs11604671 in exon 6 & $\mathrm{G} / \mathrm{G}$ & $17(68.0 \%)$ & $18(72.0 \%)$ \\
\hline \multirow[t]{2}{*}{ (p.G318R) } & $\mathrm{G} / \mathrm{A}$ & $7(28.0 \%)$ & $5(20.0 \%)$ \\
\hline & $\mathrm{A} / \mathrm{A}$ & $1(4.0 \%)$ & $2(8.0 \%)$ \\
\hline \multirow[t]{2}{*}{ Allelle frequency } & G & $82.0 \%$ & $82.0 \%$ \\
\hline & A & $18.0 \%$ & $18.0 \%$ \\
\hline rs4938016 in exon 8 & $\mathrm{C} / \mathrm{C}$ & $14(56.0 \%)$ & $12(48.0 \%)$ \\
\hline \multirow[t]{2}{*}{ (p.G442R) } & $\mathrm{C} / \mathrm{G}$ & $9(36.0 \%)$ & $10(40.0 \%)$ \\
\hline & $\mathrm{G} / \mathrm{G}$ & $2(8.0 \%)$ & $3(12.0 \%)$ \\
\hline \multirow[t]{2}{*}{ Allelle frequency } & $\mathrm{C}$ & $74.0 \%$ & $68.0 \%$ \\
\hline & G & $26.0 \%$ & $32.0 \%$ \\
\hline rs2734849 in exon 8 & $\mathrm{~A} / \mathrm{A}$ & $17(68.0 \%)$ & $18(72.0 \%)$ \\
\hline \multirow[t]{2}{*}{ (p.H490R) } & $\mathrm{A} / \mathrm{G}$ & $7(28.0 \%)$ & $5(20.0 \%)$ \\
\hline & $\mathrm{G} / \mathrm{G}$ & $1(4.0 \%)$ & $2(8.0 \%)$ \\
\hline \multirow[t]{2}{*}{ Allelle frequency } & A & $82.0 \%$ & $82.0 \%$ \\
\hline & G & $18.0 \%$ & $18.0 \%$ \\
\hline rs2734848 in exon 8 & $\mathrm{C} / \mathrm{C}$ & $0(0.0 \%)$ & $0(0.0 \%)$ \\
\hline \multirow[t]{2}{*}{$(p . Y 561 Y)$} & $\mathrm{C} / \mathrm{T}$ & $4(16.0 \%)$ & $5(20.0 \%)$ \\
\hline & $\mathrm{T} / \mathrm{T}$ & $21(84.0 \%)$ & $20(80.0 \%)$ \\
\hline \multirow[t]{2}{*}{ Allelle frequency } & $\mathrm{C}$ & $8.0 \%$ & $10.0 \%$ \\
\hline & $\mathrm{T}$ & $92.0 \%$ & $90.0 \%$ \\
\hline rs1800497 in exon 8 & $\mathrm{~A} / \mathrm{A}$ & $14(56.0 \%)$ & $6(24.0 \%)$ \\
\hline \multirow[t]{2}{*}{ (P.E713 K) } & $\mathrm{A} / \mathrm{G}$ & $10(40.0 \%)$ & $12(48.0 \%)$ \\
\hline & $\mathrm{G} / \mathrm{G}$ & $1(4.0 \%)$ & $7(28.0 \%)$ \\
\hline \multirow[t]{2}{*}{ Allelle frequency } & A & $76.0 \%$ & $48.0 \%$ \\
\hline & G & $24.0 \%$ & $52.0 \%$ \\
\hline
\end{tabular}

BED = binge eating disorder; $\mathrm{N}=$ number of individuals. 
A) $\mathrm{rs} 1800497$

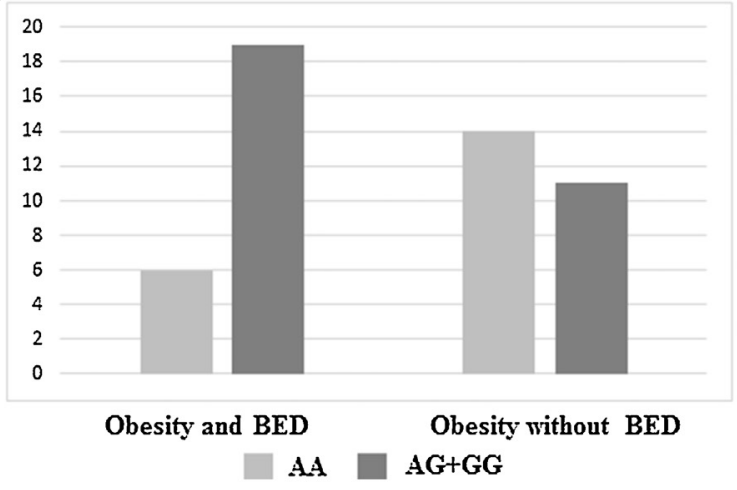

\section{B) $\mathrm{rs} 4938013$}

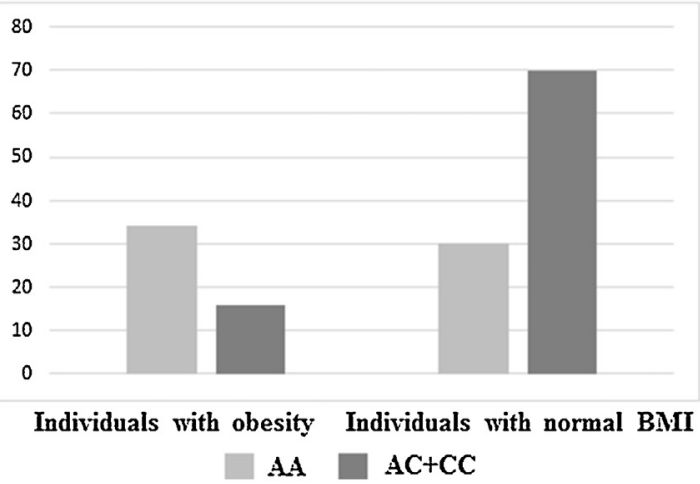

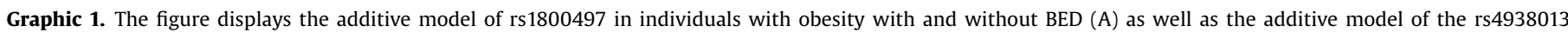
polymorphism in individuals with obesity and individuals with normal BMI.

Table 3

Genotype and allele frequencies of ANKK1 polymorphisms in obese patients (with or without BED) and individuals with normal BMI.

\begin{tabular}{|c|c|c|c|}
\hline dbSNP & Genotype frequencies & Individuals with normal BMI $(\mathrm{N}=100)$ & Individuals with obesity $(\mathrm{N}=50)$ \\
\hline rs4938013 in exon 2 & $\mathrm{~A} / \mathrm{A}$ & $30(30.0 \%)$ & $34(68.0 \%)$ \\
\hline \multirow[t]{2}{*}{ (p.I151I) } & $\mathrm{A} / \mathrm{C}$ & $53(53.0 \%)$ & $13(26.0 \%)$ \\
\hline & $\mathrm{C} / \mathrm{C}$ & $17(17.0 \%)$ & $3(6.0 \%)$ \\
\hline \multirow[t]{2}{*}{ Allelle frequency } & A & $56.50 \%$ & $81.0 \%$ \\
\hline & $\mathrm{C}$ & $43.50 \%$ & $19.0 \%$ \\
\hline rs1800497 in exon 8 & $\mathrm{~A} / \mathrm{A}$ & $28(28.0 \%)$ & $20(40.0 \%)$ \\
\hline \multirow[t]{2}{*}{ (P.E713 K) } & $\mathrm{A} / \mathrm{G}$ & $48(48.0 \%)$ & $22(44.0 \%)$ \\
\hline & $\mathrm{G} / \mathrm{G}$ & $24(24.0 \%)$ & $8(16.0 \%)$ \\
\hline \multirow[t]{2}{*}{ Allelle frequency } & A & $52.0 \%$ & $62.0 \%$ \\
\hline & G & $48.0 \%$ & $38.0 \%$ \\
\hline
\end{tabular}

$\mathrm{BMI}=$ body mass index; $\mathrm{BED}=$ binge eating disorder; $\mathrm{N}=$ number of individuals.

genetic models analyzed (Table 4, Graphic 1 ). In addition, we did not find any association with obesity, with any other of the polymorphisms described (data not shown).

\section{Discussion}

Obesity and BED have common characteristics but are not necessarily related. It has been suggested that dopaminergic dysfunction is implicated on the pathophysiology of both, obesity and BED. Dopamine is considered the main modulator of the brain reward system and regulates food intake in a significant manner [21-23]. Furthermore, genetic variations in ANKK1/DRD2 have been reported in patients with obesity and/or BED [15-17].

Taking into consideration that both obesity and BED have a genetic predisposition and that the genetic correlation between both has been determined in different ethnic groups [11,16-18,24], it is important to establish the possible presence of mutations in different populations from different ethnicities, since genomic variation is greater when compared across ethnicities. Therefore, in the present study we analyzed all coding regions of ANKK1 in individuals with obesity, with or without BED, who pertain to a specific ethnic group not studied before. After carrying out the analysis of the complete sequence of $A N K K 1$, we did not find any mutations. In spite that the design of the study was intended for trying to find mutations in the encoding sequence of ANKK1 and not for finding possible associations of genetic variants, we observed an association of rs4938013 with obesity, as well as an association of rs1800497 with the presence of BED.

Jönsson et al. [25] performed, in healthy individuals, a study in which they analyzed the possible association of DRD2 polymorphisms and striatal dopamine D2 receptor density, finding that carriers of the A allele (TaqA1 allele) of rs1800497 presented a lower density of dopamine receptors. Likewise, the A allele (Taq1A1) of rs1800497, has been associated with an increased risk for alcoholism [26,27] and opioid dependence [28]. Davis et al. [11], studied three functional SNPs, including rs1800497, in individuals with obesity with and without BED, finding that individuals with BED presented the G allele (Taq1A2) of rs 1800497 more frequently, in comparison with patients with obesity. Taking into consideration what has been described previously $[25,29]$ that

Table 4

Genetic model analyses of the association between the ANKK1 rs4938013 polymorphism and the presence of obesity.

\begin{tabular}{|c|c|c|c|c|}
\hline $\begin{array}{l}\text { rs4938013 (p.I151I) } \\
\text { Genetic Models }\end{array}$ & Genotype & OR (95\% C.I.) & $P$-value & FDR-corrected $P$-value \\
\hline Allele & A vs. C & $0.305(0.172-0.540)$ & 0.00003 & 0.00006 \\
\hline Recessive & AA vs. CC & $0.156(0.042-0.584)$ & 0.00272 & 0.00544 \\
\hline Dominant & AA vs. AC & $0.216(0.099-0.472)$ & 0.00007 & 0.00014 \\
\hline Additive & $\mathrm{AA} v s . \mathrm{AC}+\mathrm{CC}$ & $0.202(0.097-0.419)$ & $9.172 \mathrm{e}-06$ & $1.8344 \mathrm{E}-06$ \\
\hline
\end{tabular}

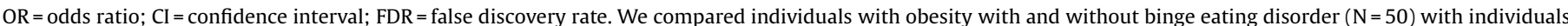
with normal BMI $(\mathrm{N}=100)$. 
the Taq1 A2 allele ( $\mathrm{G}$ allele) is associated with a $30-40 \%$ increase in dopamine D2 receptors in the striatum, when compared to the Taq1A1 allele (A allele), Davis et al. [11], suggested that the presence of the Taq1A2 allele ( $G$ allele), in combination with other SNPs, could reflect an hedonic-enhancer in individuals with BED. Furthermore, the same group of researchers analyzed several polymorphisms of DRD2/ANKK1 in subjects with obesity, with or without BED, categorizing four BED sub-phenotypes. These authors found that $70 \%$ of individuals with BED (all the subphenotypes included), exhibited the A1-genotype (Taq1A2 A2 genotype; G/G genotype) of rs1800497 [17]. Based on the known functionality of this SNP, it was concluded that BED is distinguished by a higher D2 binding potential [29] and by a greater density of D2 receptors [25], when these findings were compared to individuals with obesity without BED. Similarly, we also found that the Taq1A2 allele ( $\mathrm{G}$ allele) is the risk allele and was more frequent in individuals with obesity and BED (52\%), when compared with individuals with obesity without BED (24\%), being these differences statistically significant. Interestingly, in divergence to the studies performed by Davis et al. [11,17], where they analyzed Caucasian and African-origin populations, describing a very low frequency of the AA genotype (Taq1A1/A1), we found a higher frequency of this genotype in Mexican-Mestizo individuals. Our population (individuals with obesity, with or without BED) had the highest frequency (40\%) of the Taq1A1A1 (AA genotype), when compared to Caucasian (5.3\%), Han Chinese (20.9\%), Japanese (16.3\%), or African (16.1\%) individuals (https://www.ncbi.nlm.nih. gov/projects/SNP/snp_ref.cgi?rs=1800497); this frequency was significantly higher than the one we observed in our subjects with normal BMI (28\%).

Noteworthy, the frequency of the A allele (Taq1A1 allele) in our study (62\%), is similar to those findings reported by Panduro et al., [27] in Nahuas and Huicholes (67\% and 65\%, respectively), two different ethnic groups from Mexico. Together, these results confirm that those differences in the frequency of alleles and genotypes described in our population, in relation to other ethnic groups, may be due to our genetic background, since it has been documented that the genetic structure of our population has a predominant Amerindian ancestry [30].

Concerning the rs4938013 polymorphism in exon 2, only Lee et al., [31] have conducted an association study of this SNP. These authors studied schizophrenic individuals of Korean ethnic origin, evaluating the response to clozapine treatment, finding a borderline association of the $C$ allele with those not responders to clozapine. Regarding our results, we found a significant association of this SNP with obesity in all genetic models analyzed. Remarkably, diverging with the study performed by Lee et al. [31], in our patients with obesity the A allele was the risk allele. Likewise, the distribution of the A allele of rs4938013 is our population is different when compared to Caucasian (32.3\%), Han Chinese (54.7\%), Japanese (41.9\%) or African (22.3\%) individuals (https://www.ncbi.nlm.nih.gov/projects/SNP/snp_ref.cgi? rs $=4938013$ ).

The rs4938013 is a synonymous polymorphism (Ile151Ile) and in general, these kinds of SNPs are considered functionally neutral [32]. However, the non-neutrality of synonymous codons could be drawn from the study on synonymous codon usage bias (SCUB) $[33,34]$. On these bases, synonymous mutations do not change the amino acid sequence in proteins but can interrupt the formation of correct mRNA secondary structures [35], reduce translational accuracy and speed [36,37], and even alter the start of transcription [38]. In accordance with the latter, we could hypothesize that the codon with the polymorphic A allele (ATA) of rs4938015, influences the local rate of translation (http://www.kazusa.or.jp/ codon/cgi-bin/showcodon.cgi? species=9606).
This study has the limitation that the cross-sectional design does not allow us to determine a causal relationship between the SNPs found in ANKK1 on obesity or on BED. Despite this limitation, the strength of the study is that the statistical power observed was $>80 \%$, and the $P<0.05$, based on an additive model, as well as by the frequency of the minor allele and the prevalence of obesity or BED on our population. For this study, the number of individuals for both SNPs was sufficient to derive strong statistical power; however, to determine if the association of rs1800497 is maintained in other genetic models (dominant and additive), after correcting by a post hoc test, it will be necessary to increase the sample size.

In conclusion, to our knowledge, this is the first study establishing the relationship of rs4938013 of ANKK1 with obese patients; besides, this study reconfirms previous findings that rs1800497 might play a role in the etiology of BED in individuals with obesity.

Likewise, we observed important differences in the distribution of alleles and genotypes of these polymorphisms in our population, in comparison to what has been previously described in other ethnic groups. Further studies, directed towards the correlation between these polymorphisms with obesity, with or without BED, in other populations with a larger number of individuals, would be helpful to elucidate the true clinical implications of these polymorphisms on these pathological entities.

\section{Ethical approval}

"All procedures performed in studies involving human participants were in accordance with the ethical standards of the institutional and/or national research committees and with the 1964 Helsinki declaration and its later amendments or comparable ethical standards."

\section{Informed consent}

"Informed consent was obtained from all individuals included in the study."

\section{Acknowledgments}

Adriana Palacios was supported by a Consejo Nacional de Ciencia y Tecnología (CONACyT), México, fellowship award.

We thank the Obesity Clinic and the Blood Bank, of the Instituto Nacional de Ciencias Médicas y Nutrición "Salvador Zubirán”, México for their support.

\section{References}

[1] Encuesta Nacional de Salud y Nutrición de Medio Camino. (ENSANUT MC) Cuernavaca. Mexico: Instituto Nacional de Salud Pública; 2016.

[2] Chouinard VA, Pingali SM, Chouinard G, Henderson DC, Mallya SG, Cypess AM, et al. Factors associated with overweight and obesity in schizophrenia, schizoaffective and bipolar disorders. Psychiatry Res 2016;237:304-10.

[3] Segura-Garcia C, Caroleo M, Rania M, Barbuto E, Sinopoli F, Aloi M, et al. Binge Eating Disorder and Bipolar Spectrum disorders in obesity: psychopathological and eating behaviors differences according to comorbidities. J Affect Disord 2017;208:424-30.

[4] Pagoto S, Bodenlos JS, Kantor L, Gitkind M, Curtin C, Ma Y. Association of major depression and binge eating disorder with weight loss in a clinical setting. Obesity 2007; $15: 2557-9$

[5] American Psychiatric Association. Diagnostic and statistical manual of mental disorders. fifth edition Washington, DC: American Psychiatric Association; 2013.

[6] Kessler RC, Berglund PA, Chiu WT, Deitz AC, Hudson JI, Shahly V, et al. The prevalence and correlates of binge eating disorder in the World Health Organization World Mental Health Surveys. Biol Psychiatry 2013;7:904-14.

[7] Grilo CM, White MA, Barnes RD, Masheb RM. Psychiatric disorder comorbidity and correlates in an ethnically diverse sample of obese patients with binge eating disorder in primary care settings. Compr Psychiatry 2013;54:209-16. 
[8] Reichborn-Kjennerud T, Bulik C, Tambs K, Harris J. Genetic and environmental influences on binge eating in the absence of compensatory behaviours: a population-based twin study. Int J Eat Disord 2004;36:307-14.

[9] Javaras KN, Laird NM, Reichborn-Kjennerud T, Bulik CM, Pope Jr HG, Hudson JI. Familiality and heritability of binge eating disorder: results of a case-control family study and a twin study. Int J Eat Disord 2008;41:174-9.

[10] Hinney A, Volckmar AL. Genetics of eating disorders. Curr Psychiatry Rep 2013;15:423.

[11] Davis CA, Levitan RD, Reid C, Carter JC, Kaplan AS, Patte KA, et al. Dopamine for "wanting" and opioids for "liking": a comparison of obese adults with and without binge eating. Obesity (Silver Spring, Md) 2009;17:1220-5.

[12] Samek DR, Bailey J, Hill KG, Wilson S, Lee S, Keyes MA, et al. A Test-replicate approach to candidate gene research on addiction and externalizing disorders: a collaboration across five Longitudinal Studies. Behav Genet 2016;46:608-26.

[13] Neville MJ, Johnstone EC, Walton RT. Identification and characterization of ANKK1: a novel kinase gene closely linked to DRD2 on chromosome band 11q23.1. Hum Mutat 2004;23:540-5.

[14] Hoenicka J, Quinones-Lombrana A, Espana-Serrano L, Alvira-Botero X, Kremer L, Perez-Gonzalez R, et al. The ANKK1 gene associated with addictions is expressed in astroglial cells and upregulated by apomorphine. Biol Psychiatry 2010;67:3-11.

[15] Felsted JA, Ren X, Chouinard-Decorte F, Small DM. Genetically determined differences in brain response to a primary food reward. J Neurosci 2010;30:2428-32.

[16] Davis C, Levitan RD, Kaplan AS, Carter J, Reid C, Curtis C, et al. Reward sensitivity and the D2 dopamine receptor gene: a case-control study of binge eating disorder. Prog Neuropsychopharmacol Biol Psychiatry 2008;32:620-8.

[17] Davis C, Levitan RD, Yilmaz Z, Kaplan AS, Carter JC, Kennedy JL. Binge eating disorder and the dopamine D2 receptor: genotypes and sub-phenotypes. Prog Neuropsychopharmacol Biol Psychiatry 2012;38:328-35.

[18] Yeh J, Trang A, Henning SM, Wilhalme H, Carpenter C, Heber D, et al. Food cravings. Food cravings, food addiction, and a dopamine-resistant (DRD2 A1) receptor polymorphism in Asian American college students. Asia Pac J Clin Nutr 2016;25:424-9.

[19] Gorodezky C, Alaez C, Vázquez-García MN, de la Rosa G, Infante E, Balladares S, et al. The genetic structure of Mexican Mestizos of different locations: tracking back their origins through MHC genes, blood group systems, and microsatellites. Hum Immunol 2001;62:979-91.

[20] Miller SA, Dykes DD, Polesky HF. A simple salting out procedure for extracting DNA from human nucleated cells. Nucleic Acids Res 1988;16:1215.

[21] Narayanaswami V, Thompson AC, Cassis LA, Bardo MT, Dwoskin LP. Diet induced obesity: dopamine transporter function, impulsivity and motivation. Int J Obes 2013;37:1095-103.

[22] Blum K, Thanos PK, Gold MS. Dopamine and glucose, obesity, and reward deficiency syndrome. Front Psychol 2014;5:919.
[23] Kessler RM, Hutson PH, Herman BK, Potenza MN. The neurobiological basis of binge-eating disorder. Neurosci Biobehav Rev 2016;63:223-38.

[24] Steiger H, Thaler L, Gauvin L, Joober R, Labbe A, Israel M, et al. Epistatic interactions involving DRD2, DRD4, and COMT polymorphisms and risk of substance abuse in women with binge-purge eating disturbances. J Psychiatr Res 2016;77:8-14.

[25] Jönsson EG, Nöthen MM, Grünhage F, Farde L, Nakashima Y, Propping P, et al. Polymorphisms in the dopamine D2 receptor gene and their relationships to striatal dopamine receptor density of healthy volunteers. Mol Psychiatry 1999;4:290-6.

[26] Munafò MR, Matheson IJ, Flint J. Association of the DRD2 gene Taq1A polymorphism and alcoholism: a meta-analysis of case-control studies and evidence of publication bias. Mol Psychiatry 2007;12:454-61.

[27] Panduro A, Ramos-Lopez O, Campollo O, Zepeda-Carrillo EA, Gonzalez-Aldaco K, Torres-Valadez R, et al. High frequency of the DRD2/ANKK1 A1 allele in Mexican Native Amerindians and Mestizos and its association with alcohol consumption. Drug Alcohol Depend 2017;172:66-72.

[28] Deng XD, Jiang H, Ma Y, Gao Q Zhang B, Mu B, et al. Association between DRD2/ ANKK1 TaqIA polymorphism and common illicit drug dependence: evidence from a meta-analysis. Hum Immunol 2015;76:42-51.

[29] Noble EP, Blum K, Ritchie T, Montgomery A, Sheridan PJ. Allelic association of the D2 dopamine receptor gene with receptor binding characteristics in alcoholism. Arch Gen Psychiatry 1991;48:648-54.

[30] Lisker R, Ramirez E, Perez-Briceño R, Granados J, Babinsky V. Gene frequencies and admixture estimates in four Mexican urban centers. Hum Biol 1990;62:791-801.

[31] Lee ST, Ryu S, Kim SR, Kim MJ, Kim S, Kim JW, et al. Association study of 27 annotated genes for clozapine pharmacogenetics validation of preexisting studies and identification of a new candidate gene, ABCB1, for treatment response. Clin Psychopharmacol 2012;32:441-8.

[32] Yang Z. PAML 4: phylogenetic analysis by maximum likelihood. Mol Biol Evol 2007:24:1586-91.

[33] Plotkin JB, Kudla G. Synonymous but not the same: the causes and consequences of codon bias. Nat Rev Genet 2011;12:32-42.

[34] Komar AA. The Yin and Yang of codon usage. Hum Mol Genet 2016;25:R77-85.

[35] Saunders R, Deane CM. Synonymous codon usage influences the local protein structure observed. Nucleic Acids Res 2010;38:6719-28.

[36] Drummond DA, Wilke CO. Mistranslation-induced protein misfolding as a dominant constraint on coding-sequence evolution. Cell 2008;134:341-52.

[37] Presnyak V, Alhusaini N, Chen YH, Martin S, Morris N, Kline N, et al. Codon optimality is a major determinant of mRNA stability. Cell 2015;160:1111-24.

[38] Stergachis AB, Haugen E, Shafer A, Fu W, Vernot B, Reynolds A, et al. Exonic transcription factor binding directs codon choice and affects protein evolution. Science 2013;342:1367-72. 